\title{
Sizewell inquiry leaves questions unanswered
}

\section{London}

DESPITE having placed much confidence in the assurances of the Central Electricity Generating Board (CEGB) and the Nuclear Installations Inspectorate (NII) on the safety aspects of the pressurized water reactor (PWR), the Layfield Inquiry was scathing in its criticisms of the poor communications between the two bodies.

Managerial and procedural weaknesses stand out despite the complexity of the licensing processes, which require "highly efficient exchange" of complex information. Layfield claims that although no evidence was submitted that suggested that those managerial weaknesses "have affected the thoroughness with which safety problems have been tackled or the level of safety achieved by the proposed Sizewell B design", there was stark evidence of confusion over responsibility and agreed safety standards.

Neither NII nor CEGB was totally responsible for these ambiguities. claims the report, and the government must share the blame. There has been little or no parliamentary or governmental guidance on how the licensing process should be carried out or on the basis for safety assessment, says Layfield.

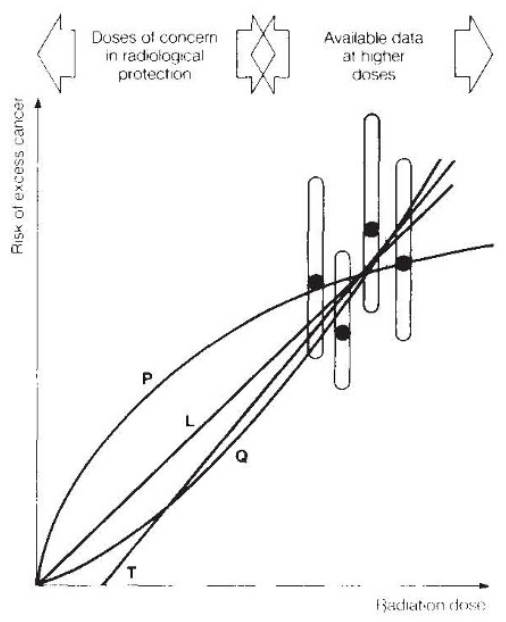

Fig. 1 The black circles show the excess of cancer observed in four groups of people exposed to different absorbed doses of X-rays. The vertical error bars represent the range of uncertainty in the observations. Four assumptions were suggested for extrapolating these data to obtain a relationship between dose and rate of excess cancers at low doses. (1) The excess öf cancer is proportional to the absorbed dose, as represented by the straight line. (2) A relationship represented by the curve $Q$, whose general shape is developed from experimental and theoretical radiobiology, but whose exact shape cannot be predicted for humans. (3) A relationship represented by the curve $\mathrm{P}$, which would fit excess cancers observed in workers at the Hanford atomic plant in the United States. (4) There is a threshold dose below which there is no risk of radiation-induced cancer, as represented by the line $\mathrm{T}$.
The high level of mutual understanding needed between CEGB and NII is not helped by the "lack of sufficiently clear and agreed safety criteria" and the existence of different safety criteria that "was perplexing to the objectors and is likely to be a source of confusion to the layman".

One of the most serious deficiences in the relationship between the two groups was weak communications. This led to frequent misunderstandings and on occasions to "fundamental misapprehension" of each other's position.

Layfield concluded that the submission of evidence during the inquiry showed the serious weaknesses in the relationship between NII and CEGB. During the course of the inquiry, "important initiatives" were taken to improve the management but "it was too early to judge the efficiency of these new arrangements".

The susceptibility to radiation and its effects are the two primary issues that originally precipiated the inquiry. The report details much of the known effects of radiation. The principal effects of low-level radiation, the report concedes, are to increase the probability of cancer or hereditary disease which may not occur for years. The short-term ill-effects "only occur in unusual situations such as a serious accident involving radiation". The primary public fear is the development of cancer as a result of either small or large exposures to radiation.

Because cancer is a common disease, now claiming one in every five deaths, it is difficult to assess easily the cancer that would not be expected to occur naturally, claims the study. Says Layfield: "In groups exposed to ionising radiation the excess of cancer due to radiation is likely to be small compared with variations in the natural incidence of cancer. Estimates of excess cancers are therefore likely to be subject to considerable uncertainty."

The exact shape of the dose-response relationship for radiation-induced cancers cannot yet be predicted "with confidence for humans". Four assumptions have been made about this relationship (Fig. 1).

The evaluation of the risk is as important as the risk itself. Nuclear power is widely considered, says Layfield, to be unique in the nature of the risks it poses but "risks similar to those often thought to be unique to nuclear power are associated with some other industries".

Carcinogenic chemicals that are imperceptible to the senses can be released in an accident in a chemical plant. And techniques for numerically estimating the risks from nuclear power have only recently been developed, says the report, and "the results of such estimates are subject to considerable uncertainty".

On the criteria available, Layfield has

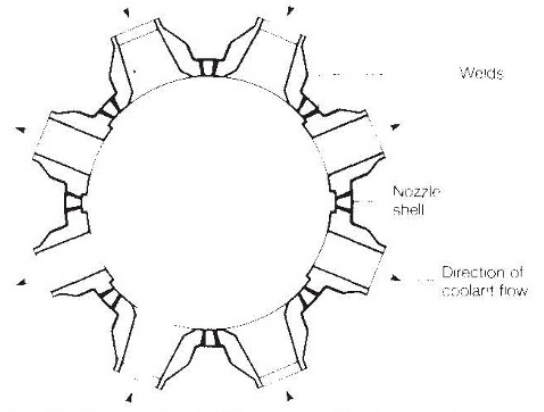

Fig. 2 The main differences between the conventional integral design and that to be used at Sizewell (above) are: (1) The shell flange and nozzle ring are made of a single forging in the integral design as opposed to two forgings welded together: (2) In the integral design the nozzles are not welded into holes in the nozzle ring, but to its outer surface. Thus the holes in the nozzle ring correspond to the inner rather than the outer diameter of the nozzles. (3) In the integral design the weight of the vessel and its contents is supported by special stubs attached to the outside of the vessel, whereas the Sizewell B design is supported on four of the eight nozzles. Thus the integral design potentially reduces stresses where the nozzles join the nozzle shell, a region where the stress distribution is complex. (4) The thickness of the integral vessel is greater than that of the Sizewell $B$ vessel.

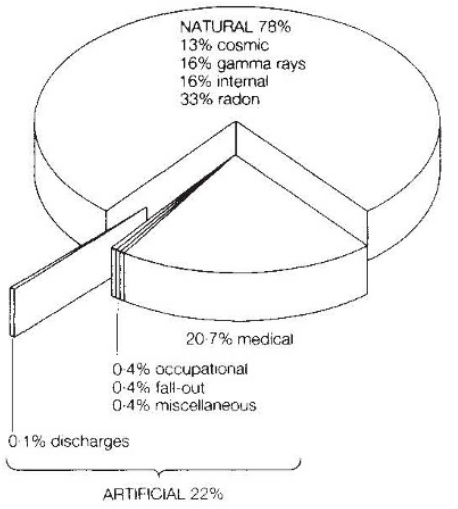

Fig. 3 The sources of radiation to the UK population.

determined what he considers a "tolerable risk". Any system of risk evaluation must take account of the special factors that might distinguish that risk, says the study. The nuclear industry is unique in the eyes of the public Layfield admits.

"The attitudes of members of the public who were worried about the safety of Sizewell $\mathrm{B}$ demonstrated that any system of risk evaluation must take account of special factors which distinguish the risk being examined. Many people regard the risks from nuclear power as having a special character, with the consequence that these risks should be regarded with more seriousness than other risks nominally of a similar size. One way of deciding on a tolerable level of risk is to find out what risks the public is already known to tolerate" (Fig. 3).
Bill Johnstone 